\title{
Diferenças regionais de café da manhã em uma rede hoteleira no Brasil
}

\author{
Regional differences in breakfast in a hotel chain in Brazil \\ Diferencias regionales de desayuno en una red de hoteles en Brasil
}

Recebido: 18/01/2022 | Revisado: 22/01/2022 | Aceito: 24/01/2022 | Publicado: 25/01/2022

\author{
Gisele Estevão de Lima \\ ORCID: https://orcid.org/0000-0003-1901-8078 \\ Instituto Federal de Pernambuco, Brasil \\ E-mail: Giselleestevao@gmail.com \\ Joásia Xavier da Silva \\ ORCID: https://orcid.org/0000-0003-4975-1262 \\ Instituto Federal de Pernambuco, Brasil \\ E-mail: joasiaxavier@gmail.com \\ Rodrigo Rossetti Veloso \\ ORCID: https://orcid.org/0000-0002-0510-0882 \\ Instituto Federal de Pernambuco, Brasil \\ E-mail: rodrigo.rossetti@cabo.ifpe.edu.br \\ Neide Kazue Sakugawa Shinohara \\ ORCID: https://orcid.org/0000-0001-8356-874X \\ Universidade Federal Rural de Pernambuco, Brasil \\ E-mail: neide.shinohara@ufrpe.br
}

\begin{abstract}
Resumo
Não existe relação mais intima do que a do homem com o ato da alimentação. O que se come, como se come e onde se come, definem qual a cultura alimentar que se está inserido. A intrínseca relação entre o turismo e a gastronomia sempre ocorreu, porém pouco percebido ou estudado em trabalhos acadêmicos. Este levantamento teve como objetivo comparar as preparações culinárias oferecidas no café da manhã de uma rede hoteleira no Brasil e identificar diferenças da cozinha regional, com o intuito de garimpar evidências de que existem diferenças regionais no Brasil e que estas diferenças foram marcados inicialmente pelas culturas indígena, africana e portuguesa e mais recente pelos estrangeiros de diferentes regiões da Europa, ocorrendo a hibridização com nossos valores culinários, contribuindo para a regionalização do café da manhã. Esse fato peculiar de consumo demonstra que o desjejum matinal nos hotéis é um potencial inexplorado pelo trade hoteleiro nacional.
\end{abstract}

Palavras-chave: Desjejum matinal; Hotel; Regionalização alimentar.

\begin{abstract}
There is no more intimate relationship than that of man with the act of eating. What you eat, how you eat and where you eat define which food culture you are in. The intrinsic relationship between tourism and gastronomy has always occurred, but little noticed or studied in academic works. This survey aimed to compare the culinary preparations offered for breakfast in a hotel chain in Brazil and to identify differences in regional cuisine, in order to gather evidence that there are regional differences in Brazil and that these differences were initially marked by indigenous cultures. African and Portuguese and more recently by foreigners from different regions of Europe, hybridizing with our culinary values, contributing to the regionalization of breakfast. This peculiar fact of consumption demonstrates that breakfast in hotels is an untapped potential for the national hotel trade.
\end{abstract}

Keywords: Breakfast; Hotel; Food regionalization.

\section{Resumen}

No hay relación más íntima que la del hombre con el acto de comer. Lo que comes, cómo comes y dónde comes define en qué cultura alimentaria te encuentras. La relación intrínseca entre turismo y gastronomía siempre se ha dado, pero poco advertida o estudiada en los trabajos académicos. Esta encuesta tuvo como objetivo comparar las preparaciones culinarias que se ofrecen para el desayuno en una cadena hotelera en Brasil e identificar las diferencias en la cocina regional, con el fin de recopilar evidencias de que existen diferencias regionales en Brasil y que estas diferencias fueron inicialmente marcadas por las culturas indígenas, africanas. y portugueses y más recientemente por extranjeros de diferentes regiones de Europa, hibridando con nuestros valores culinarios, contribuyendo a la regionalización del desayuno. Este peculiar hecho de consumo demuestra que el desayuno en los hoteles es un potencial desaprovechado para la hostelería nacional.

Palabras clave: Desayuno; Hotel; Regionalización alimentaria. 


\section{Introdução}

$\mathrm{Na}$ antropologia, a cultura pode ser entendida como um sistema simbólico, ou seja, um conjunto de mecanismos de controle, planos, receitas, regras e instruções que governam o comportamento humano. Esses símbolos e significados são partilhados entre os membros do sistema cultural, assumindo um caráter público e, portanto, não individual ou privado (Veloso et Al., 2019). A cultura alimentar brasileira é formada por um conjunto de diversas influências, composto por povos indígenas, africanos, colonizadores, história e regionalidade, o que resultou nos hábitos miscigenados que nos favoreceu na pluralidade. Dessa forma, a cultura alimentar é a expressão da identidade de diversos povos por meio da alimentação, sendo considerada como patrimônio imaterial (Santos \& Pascoal, 2013).

Os alimentos que compõem a conduta alimentar, nos define com uma força expressiva muito mais abrangente do que podemos imaginar, comer está longe de ser apenas uma questão biológica, é um ato de pertencimento capaz de se comunicar e tornar essa forma de expressão palpável, seguindo as tradições culturais regionais. Cada povo se alimenta como forma de resistência a tudo que o tempo teima em abandonar, mas que representa de forma cultural, uma identidade culinária regionalizada (Shinohara et al., 2014).

Dentre os estudos de consumo alimentar no Brasil, poucos abordam as diferenças e preferências quanto às características de preparos regionais e o uso de alimentos nativos. Essas pesquisas têm foco na quantidade de nutrientes e calorias ingeridas e na associação com os fatores socioeconômicos, sinalizando que a lista de produtos adquiridos pelos brasileiros de diferentes regiões vem apresentando mudança expressiva em decorrência da globalização alimentar, imposta pela força econômica dos alimentos industrializados (Carvalho, 2008).

Sabe-se que uma alimentação balanceada e diversificada, com a presença dos principais grupos alimentares é capaz de fornecer uma ampla variedade de nutrientes, indispensáveis à manutenção da vida e promoção da saúde (Santana \& Alves, 2022). A cultura alimentar que compõe o cardápio atual da alimentação do brasileiro é fundamentada em uma mistura de hábitos advindos do início da colonização do país, com a inserção de grande quantidade de espécies provenientes de diferentes regiões geográficas (Silva et al., 2022), que se somaram a outros fatores importantes, como os grupos sociais e poder aquisitivo, influenciando significativamente nos hábitos alimentares da população.

O termo "alimento típico" tem sido largamente utilizado como alimento ancorado às tradições locais, com produção local e significados regionais. Entende-se por cozinha regional a resultante da aliança cultural de formação, colonização ou da própria evolução. São cozinhas que perpetuam a influência da cultura gastronômica na vida social e nos costumes e estão associadas a povos em particular, constituindo aspectos da identidade e sendo a chave simbólica dos costumes (Conceição et al., 2021; Lody, 2019; Santana et al., 2021). Segundo Bueno (2016) a culinária nos tempos atuais ainda envolve ato de cozinhar empregando técnicas culinária, capaz de reunir a família e amigos, envolvendo sentimento de afetos e transmissão de conhecimentos e segredos.

O hábito de consumo de alimentos locais é pouco frequente nas regiões mais urbanas no Brasil. Vários alimentos regionais são desconhecidos pela grande maioria dos brasileiros, o que contribui para a não inserção destes recursos ignorados como hábito de consumo na rotina alimentar (Dimenstein et al., 2010; Uggioni, 2006). Os alimentos regionais são ricos nutricionalmente, incrementando como fontes alternativas e que podem ter funções terapêuticas importantes, como os compostos fenólicos, que apresentam atividade antioxidante (Orsi et al., 2012). A oferta de tais alimentos na primeira refeição do dia, pode garantir o suporte inicial ao desenvolvimento das atividades laborais do ser humano.

O consumo dos alimentos regionais pode representar uma alternativa para a resolução ou minimizar impactos deletérios dos problemas de alimentação e nutrição no país, através da reorientação de programas oficiais de educação alimentar e nutricional governamental, já que tais alimentos são quase sempre de fácil acesso e baixo custo (Sousa, 2016). Podendo e devendo ser analisado o consumo de alimentos regionais sob diversas perspectivas, sobretudo as nutricionais e 
culturais, pois o consumidor busca cada vez mais uma alimentação saudável e disponível; e o produtor procura novas oportunidades de produtos para inserção no mercado consumidor, tão ávido por novidades (Brasil, 2015).

Existe uma grande falta de definição universal para o termo café da manhã, porém a maior parte dos significados que existem incluem componentes relacionados ao tempo e tipo de alimento, no entanto, a definição de café da manhã é motivo de controvérsias por ter vários sentidos, segundo Mullan \& Sing (2010). O café da manhã é estabelecido como a primeira refeição do dia, sendo ingerido antes das 10 horas, ou a primeira refeição consumida ao acordar (Timlim \& Pereira, 2007). A descrição do café da manhã não permite um certo padrão universal, pois varia de acordo de onde o indivíduo está inserido, de acordo com a cultura, hábitos e tradição alimentar. O consumo do café da manhã traz uma contribuição significativa como atributo para compor uma dieta saudável, de acordo com a ingesta necessária de vários grupos alimentares que consumimos no desjejum, nos motiva para as atividades diárias (Affenito, 2007).

A relação entre Gastronomia e turismo não é nova novidade no campo da conveniência humana. No século IV d.C. um grego chamado Archestreatus viajou pelo mediterrâneo e registrou com detalhes suas descobertas sobre o que comia e bebia em cada região visitada. Porém, apenas no século XX é que se avistou a gastronomia como produto turístico, oferecendo aos visitantes que já não se satisfaziam somente com aparelhos turísticos, como o sol e a praias, mas também com locais da culinária típica (Uribe et al., 2017).

Uma empresa hoteleira, por definição, tem como característica oferecer alojamento em unidade habitacional aos seus clientes. Além disso, proporciona serviços auxiliares como alimentação, lazer e promoção de eventos. O sistema hoteleiro dividido em três grandes setores: Hospedagem, que envolve a área dos apartamentos e suas áreas sociais; Administração, que é o setor que administra e controla as atividades com a finalidade de garantir e dar condições para o bom funcionamento dos demais setores; e Alimentos e Bebidas, que abrange cozinha, restaurante, sendo responsável pela preparação da alimentação ao cliente (Trintin \& Hahn, 2021). Em relação a alimentos, a maioria dos hotéis no Brasil inclui no valor da diária o café da manhã, sendo este um serviço essencial para a satisfação plena de acomodação do cliente.

Essa pesquisa promoveu a análise e discussão sob diversas óticas quanto ao do café da manhã servido em hotéis de uma rede hoteleira internacional, no contexto da soberania e cultura alimentar servida em diferentes regiões brasileiras.

\section{Metodologia}

A metodologia deste trabalho está estruturada em duas partes. A primeira parte é composta pelos procedimentos adotados para conduzir uma revisão bibliográfica que forneceu suporte teórico no que se refere à forma de abordagem das pesquisas existentes sobre o tema "Diferenças regionais no café da manhã em hotéis no Brasil".

O tipo de revisão escolhida foi a integrativa, que articula dados da literatura teórica e empírica, além de agregar propósitos como definição de conceitos, revisão de teorias e evidências, e análise de problemas metodológicos de um tópico em particular. Possibilita assim, a inclusão de estudos experimentais e não-experimentais, e permite uma compreensão completa do fenômeno alimentar analisado (Souza et al., 2010).

Essa revisão integrativa teve como objetivo analisar estudos sobre o Café da manhã no Brasil e no mundo, com enfoque no consumo de alimentos regionais nessa refeição diária. A estratégia de busca de artigos dessa revisão compreendeu uma pesquisa em bases de dados do Periódico Capes, LILACS (Literatura Latino-americana e do Caribe em Ciências da Saúde), SciELO (Scientific Eletronic Library on Line) e Google Scholar, sem delimitação de tempo. A busca foi realizada exclusivamente em português, utilizando-se os descritores "desjejum", "desjejum regional", "café da manhã" e "café da manhã regional". Como a palavra "regional" em alimentação possui diversos sinônimos, também foram utilizados como descritores os substitutos "tradicional" e "típico".

A segunda parte contém a descrição do delineamento, da execução e da análise dos dados da pesquisa com os hotéis 
no território nacional. Para a participação dos hotéis na pesquisa, foi realizada uma consulta por meio telefônico e por e-mail com diversos hotéis da Rede selecionada, para verificar a sua possibilidade de participação na pesquisa. Após o aceite, houve uma conversa virtual com os gerentes, culminando com o envio pelo hotel, de uma lista completa com os itens que são ofertados no café da manhã. Para o presente trabalho, foi considerado como unidade amostral a unidade hoteleira, tendo em vista que nem todas as unidades de restaurantes ofereciam Café da Manhã. Participaram da pesquisa 15 hotéis da rede, sendo 3 unidades de cada região brasileira.

\section{Resultados e Discussão}

Algumas considerações podem ser feitas sobre os resultados encontrados na comparação entre os alimentos ofertados no café da manhã dos hotéis da rede. Inicialmente identificamos que possivelmente por ser uma rede internacional de hotéis, existe um padrão de organização, disposição, serviço e reposição. O café da manhã é organizado em forma de buffet, sempre com o mesmo padrão de disposição dos alimentos, obedecendo um agrupamento de alimentos, para aqueles que precisam tanto de temperatura quente com auxílio de réchauds, quanto fria para os alimentos que precisem de refrigeração, com auxílio de pistas fria, assim como acontece com a disposição dos demais produtos à temperatura ambiente (Figura 1).

Figura 1 - Disposição do buffet no café da manhã de um dos hotéis pesquisados hotel da região nordeste.

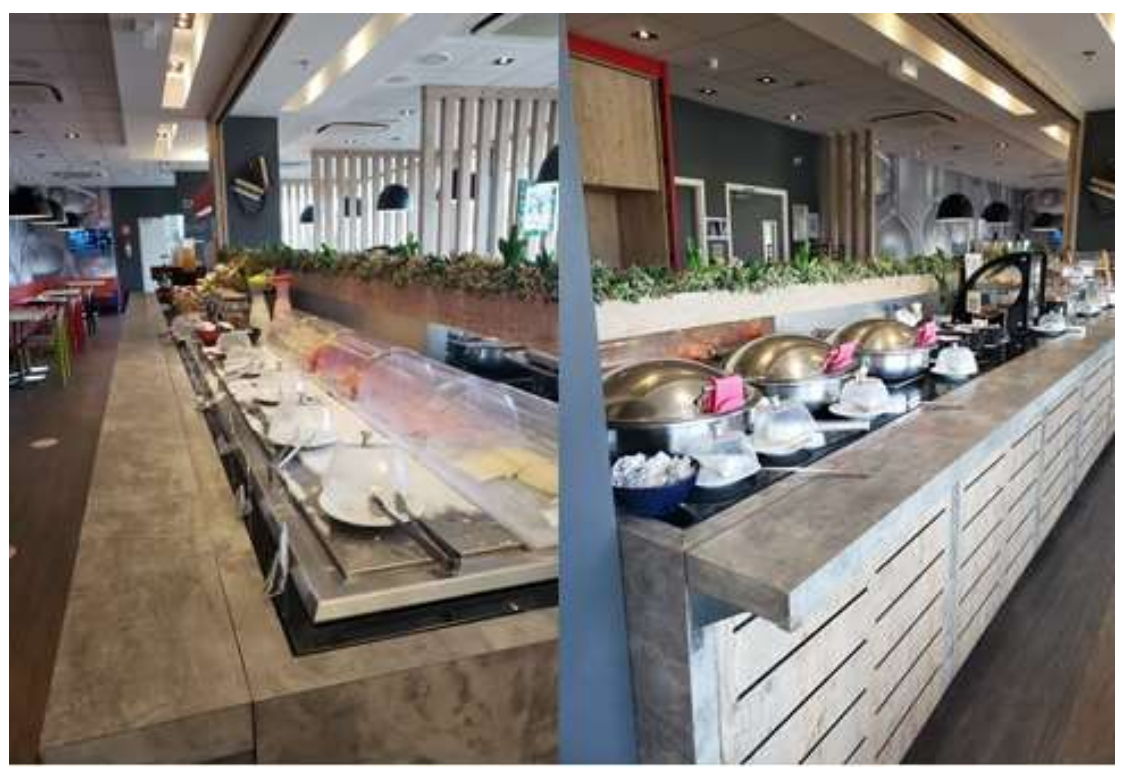

Fonte: Autores (2021).

O serviço dos atendentes é sempre discreto e essencialmente serve para retirar os pratos sujos da mesa, e para o serviço sob demanda, presente em algumas unidades, como por exemplo nas unidades do nordeste, é deixado um informe sobre a mesa, caso a hóspede queira que a tapioca seja feita na hora, bastando solicitar a equipe de apoio que realize a confecção no ato de consumo, uma vez que a tapioca perde a característica crocante original, podendo levar o hóspede a rejeição dessa preparação regional do café da manhã no nordeste brasileiro.

As bebidas ofertadas no café da manhã dos hotéis obedeceram a um padrão da rede hoteleira pesquisada, onde $100 \%$ oferecem as mesmas bebidas: Café coado e de máquina; Leite integral, desnatado e em pó; chás nacionais e importados; iogurte natural ou saborizado; sucos naturais e polpas; e água mineral. A variação encontrada nesse ponto foi na grande variedade de sucos ofertadas, onde o fator da sazonalidade é bastante importante e muitas vezes mais relevante do que os fatores de regionalismo, visto que apesar dos avanços da agroindústria nas últimas décadas, ainda existe uma variação de preço 
significativo nas frutas e tubérculos sazonais. A única ressalva é o suco de laranja natural ou industrializado (Figura 2), que é regularmente ofertado por todas as unidades hoteleiras pesquisadas no decorrer do ano.

Figura 2 - Prato de café da manhã com suco de laranja e pães no café da manhã de hotel da região nordeste.

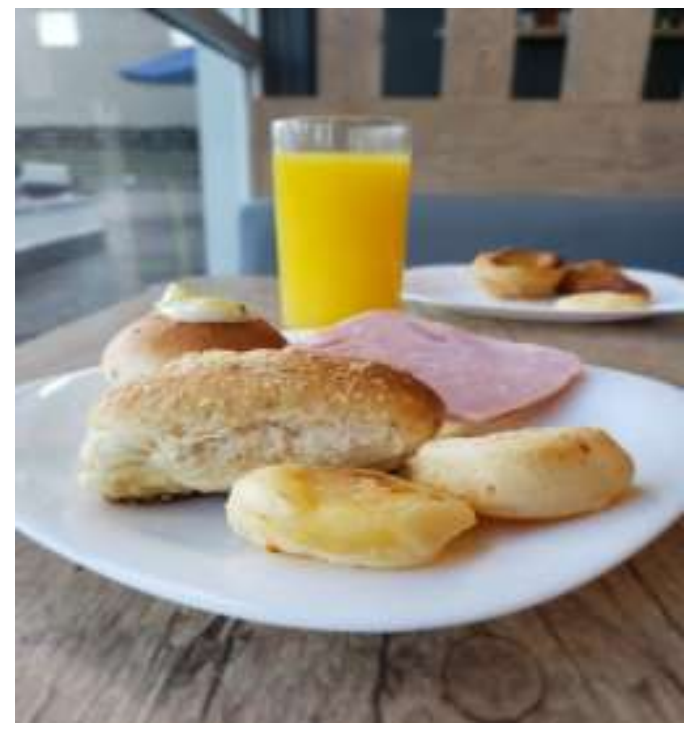

Fonte: Autores (2021).

Segundo Arruda et al. (2009), 93\% da população brasileira declara que toma a bebida café regularmente, e existe uma tendência de crescimento da quantidade consumida. O consumo no Brasil representa $13 \%$ de todo consumo mundial do café. No que tange ao leite, observamos o alto consumo per capita do brasileiro, que hoje é de aproximadamente 170 L/habitante/ano tais informações associadas ao costume de se consumir café com leite no café da manhã, além do chá, que mesmo não sendo de consumo tradicional de regiões tropicais como o Norte e o Nordeste, é usado de forma frequente nessas regiões, possivelmente por conta dos processos migratórios e de ocupação do território nacional, estimulados pelo Governo Federal nos anos de 1980 cuja prática corroborou com a oferta regular de diferentes chás em todos os hotéis pesquisados (Vilela et al., 2017; Sousa, 2016).

Os sucos representam o sexto alimento mais consumido pelos brasileiros, com mais de $40 \%$ de consumo diário, sendo também a laranja uma das frutas com maior prevalência entre o consumo nacional de sucos, devido à grande demanda de produção e preço acessível (Souza, 2013). A laranja é produzida em cerca de 100 países, cuja produção concentra-se principalmente no Brasil e Estados Unidos. O Brasil ocupa a primeira posição em produção e exportação de suco de laranja concentrado e congelado (Bastos et al., 2012).

Aparece com um grande apelo entre os hóspedes, os produtos panificáveis. Dentre os panificados todos apareceram em 100\% dos hotéis, com uma variedade de produtos como pão de forma, pão integral e pão doce, biscoitos amanteigados, croissant e pão de queijo (Figura 2). A oferta regular destes produtos se deve, principalmente pela preferência de consumo dos brasileiros, que segundo Souza et al. (2013) pesquisando os alimentos mais consumidos no Brasil, o pão foi o quarto alimento mais consumido com $63 \%$ de consumo diário. Contando na lista dos vinte alimentos mais consumidos pelos brasileiros, os salgados assados onde o croissant e o pão de queijo estão incluídos, corresponde a 12,5\% do consumo. O pão de queijo, é um alimento regional da região Sudeste que se espalhou pelas outras regiões devido a possibilidade de congelamento pela indústria de alimentos (Araújo et al., 2005).

O consumo de bolachas e biscoitos, com 15,9\% do consumo de panificáveis no território nacional. Tais dados corroboram com a justificativa da oferta desses produtos em todas as unidades hoteleiras pesquisadas. Em algumas regiões os 
pães assumem o papel de protagonistas no café da manhã, como nas regiões sul e sudeste, já em outras regiões como o norte e sudeste, seu consumo é secundário, perdendo espaço para outros alimentos regionais, como raízes, tubérculos e o cuscuz de milho, acompanhado de proteínas na forma de guisados de carne bovina ou de frango, ovos e embutidos.

Aliado aos panificados, os frios apresentam um papel relevante no café da manhã dos brasileiros e estiveram presentes em $100 \%$ das mesas de buffet no desjejum matinal nos hotéis pesquisados. Os frios aparecem tanto na composição de algumas receitas como oferecidos separadamente nos balcões refrigerados, geralmente cortados em fatias porcionados para consumo individual (Figura 2). Os mais comuns são o queijo prato, o queijo muçarela, o queijo branco, o presunto e a mortadela, além do requeijão e da manteiga, sempre oferecidos em porções individuais, com gramaturas semelhantes. Segundo Souza (2013) e Sousa (2016), os queijos muçarela e prato apresentam aproximadamente $13 \%$ de prevalência no consumo diário dos brasileiros, seguido pelos embutidos, que apresentam em média $10 \%$. Os dois grupos estão entre os 20 alimentos mais consumidos pela população brasileira e ratificam sua presença nas mesas de café da manhã nos hotéis pesquisados.

A oferta regular de bolos no café das manhãs dos hotéis já é uma prática consagrada na hotelaria. Nas unidades pesquisadas, a oferta dos bolos de trigo, também carinhosamente chamado de bolo branco, e de chocolate foram de $100 \%$. O bolo figura entre os 20 alimentos mais consumidos do Brasil com mais de 13\% de prevalência diária (Souza, 2013), ratificando a importância da oferta desses produtos para a maior aceitação e satisfação dos hóspedes.

Uma série de produtos são complementares no café da manhã e que estiveram em 100\% dos hotéis pesquisados, são eles o cereal de milho e de chocolate, achocolatado em pó, granola, mel, geleias e aveia. Ribeiro et al. (2009), constatou em sua pesquisa que mais de 50\% dos brasileiros consomem ao menos 1 vez na semana o mel, e que por suas características sensoriais e físico-químicas, sua procura e o seu consumo estão aumentando gradativamente, sendo principalmente utilizado em substituição ao açúcar. Em decorrência dessa substituição, os hotéis passaram a oferecer o mel no café da manhã. A granola apresenta uma grande variedade de ingredientes, mas sempre apresentando um valor nutricional muito adequado quando comparados com os cereais matinais de milho, apesar destes terem uma grande vantagem na preferência do público mais jovem (Mendoza et al., 2016).

O consumo de frutas no café da manhã já é um hábito no Brasil e no café da manhã dos hotéis pesquisados, estas apareceram com 100\% de frequência com os mesmos tipos de frutas ofertadas independente da época ou da região brasileira. Apresentadas cortadas ou na salada de frutas, as que apareceram na pesquisa foram o mamão formosa e o papaia, a banana, a melancia, o abacaxi e o melão. A presença da laranja é exclusivamente como opção como suco natural.

Ao longo da pesquisa observou-se que os hotéis, agrupados por região, apresentaram em seus menus, alimentos regionais que não apareceram em outros hotéis de regiões distintas, demonstrando aspectos da regionalidade. $\mathrm{O}$ regionalismo se expressa na alimentação através de hábitos e práticas alimentares, que acompanham os grupos geograficamente estabelecidos, ao longo do seu desenvolvimento e construção social e cultural (Brasil, 2015).

Os hotéis da região Nordeste apresentaram dentre as opções regionais, o cuscuz, que é uma comida de milho flocada, que compõe o desjejum do nordestino, onde o seu consumo está associado a um tempo maior de saciedade para trabalhadores que desempenham funções mais fastidioso e, ao longo do tempo se tornou característica alimentar desse povo do nordeste brasileiro (Corção, 2014; Maior, 2004).

A escolha por alimentos marcadamente regionais para compor a mesa de café da manhã dos hotéis pode-se comprovar pela escolha de uma unidade pesquisada, em Pernambuco, por oferecer entre os bolos do desjejum, o bolo de rolo (Figura 3). Preparação típica do estado, que é composto de um bolo amanteigado de massa bem fina, recheado com goiabada e enrolado, sugestivo para o nome. O bolo de rolo é patrimônio cultural imaterial do estado de Pernambuco desde 2008, e é um importante marcador cultural (Silva, 2010; Freyre, 2020). 
Figura 3 - Bolo de rolo no café da manhã de um dos hotéis pesquisados da região nordeste.

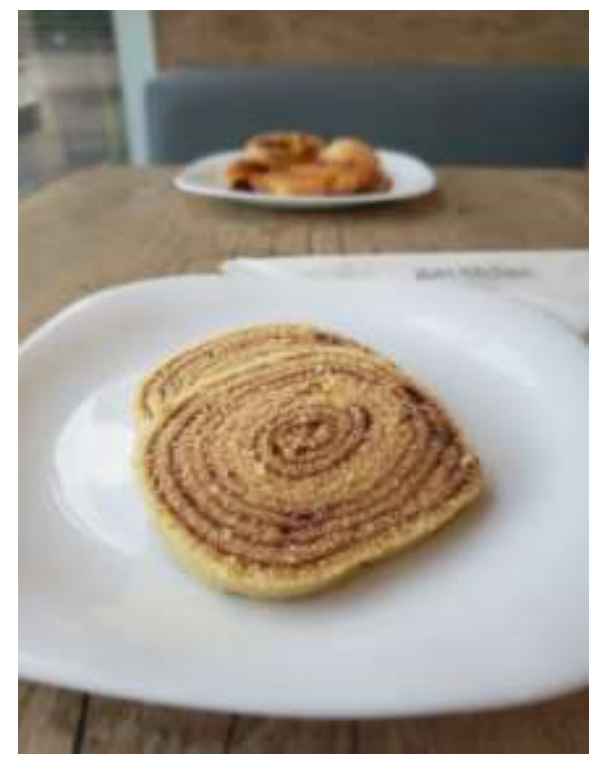

Fonte: Autores (2021).

Nos hotéis do Nordeste algumas preparações se destacam, como o cuscuz conhecido como alimento ouro do nordeste. Outras preparações ofertadas foram a macaxeira, a batata doce, o inhame, o cará e a banana comprida cozida. Observou-se a correlação da oferta destes alimentos associados a uma ou mais preparações proteicas como ovos mexidos, bacon, salsicha com molho de tomate, galinha no molho, carne de molho, calabresa acebolada, carne sol, charque ou queijo coalho frito. Por último, e não menos importante, observou-se que nos hotéis do Nordeste é ofertada a tapioca (Figura 4), sempre levado à cocção feita na hora que o hóspede pede, com recheios de coco, queijos ou coco e queijos, os queijos são os mesmos tipos dos que estão disponíveis no buffet de café da manhã do hotel.

Figura 4 - Tapioca feita na hora no café da manhã de um dos hotéis do nordeste.

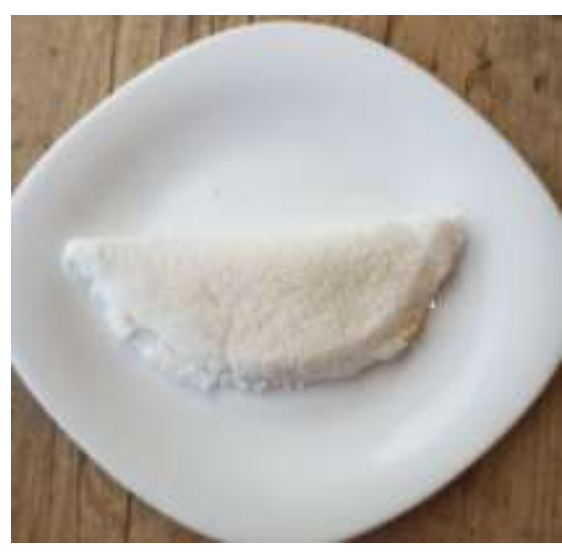

Fonte: Autores (2021).

O cuscuz (Figura 5), também conhecido tradicionalmente como pão de milho (Lima, 2009), é uma preparação originária de quase todas as regiões brasileiras, com exceção da região Sul, apresentando maior consumo nas regiões Centrooeste com 10,2\% e Nordeste com 27,9\%. Possivelmente, nas outras regiões isso se justifica pela falta de tempo das pessoas em preparar tal prato para o café da manhã. A mandioca ou macaxeira, dependendo da região (Figura 7), é um alimento muito presente na história da alimentação brasileira. É o ingrediente básico de diversas preparações brasileiras (Cascudo, 2017; Santos et al., 2020). 
Figura 5 - Prato com cuscuz, macaxeira cozida e salsicha com molho no café da manhã de um dos hotéis do nordeste.

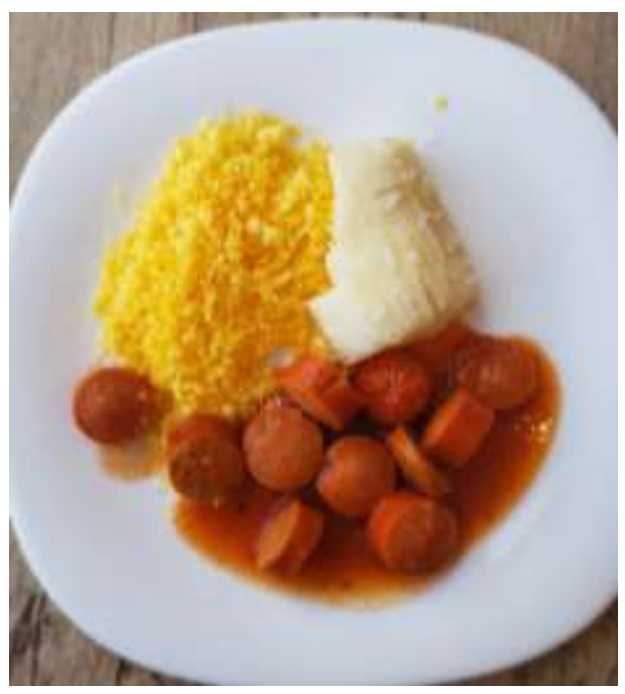

Fonte: Autores (2021).

Nos hotéis da região centro-oeste o alimento regional que é oferecido pelos hotéis e que é um marcador regional é o empadão recheados com carne ou frango, ou o famoso empadão goiano; além do biscoito de polvilho e a oferta de preparações com frutas regionais, como a salada de frutas com creme de pequi. Na região norte, existe uma influência muito grande da cultura indígena no desjejum. Os principais produtos que só foram ofertados no desjejum dos hotéis dessa região foram o beiju, o açaí e a banana assada com coco, sendo a maior parte dos alimentos regionais ofertados derivados da mandioca/macaxeira.

Na região sudeste os panificados aparecem com bastante protagonismo, mas ainda assim as peculiaridades têm seu lugar garantido, o pão com manteiga na chapa, o pão de queijo minas tradicional e uma adaptação do pão romeu e julieta; além da utilização dos embutidos e da oferta de diferentes tipos de café, como o filtrado na hora, o expresso, o instantâneo, o fervido e o saborizado, além do consumo do chá mate gelado. Vem dessa região a famosa expressão "leite com café pingado", que é um copo americano com leite bovino e pingado com café filtrado.

Nos hotéis da região no Sul, os protagonistas do café da manhã local foram os embutidos, muito por influência dos imigrantes europeus: italianos, alemães, poloneses e ucranianos, que deixaram marcas de suas culturas na culinária da região, os embutidos comuns mais presentes: copa, linguiças, salame, mortadela e salsicha acompanhados por pães artesanais e polentas, outra preparação muito característica ofertada é a cuca que pode ser feita de várias frutas, mas a oferecida pelos hotéis é a de banana, além da oferta do chimarrão como bebida de socialização e conviva.

Na região Centro-oeste os alimentos mais consumidos no café da manhã foram o pão de queijo, o pastel, o cuscuz e o presunto. O consumo de frutas no café da manhã do centro oeste é de apenas 14,3\%, essa região tem sido referenciada como região receptora de imigrantes das demais regiões do país, por isso apresenta a segunda maior taxa de urbanização do Brasil (Brasil, 2012), com os migrantes trazendo seus hábitos alimentares para a região, que nas últimas décadas foi a localização geográfica que mais cresceu em produção de alimentos em larga escala, e que propiciou a hibridização de valores alimentares de pessoas de diferentes regiões do Brasil e do mundo.

Na região Nordeste os alimentos mais consumidos no café da manhã são o cuscuz, o queijo coalho, a laranja e o maracujá. As frutas são largamente consumidas, com mais de 40\% de frequência no referido estudo. Os principais alimentos consumidos no café da manhã da região Norte foram a tapioca, o chá, o bolo de milho e a banana da terra, dando-se ênfase para o alto consumo de frutas nessa refeição, com valores passando de $40 \%$ no referido estudo.

No sul do país, os alimentos mais consumidos no café da manhã são: presunto, geleia de frutas, mortadela e o doce de leite (Sousa, 2016), tal diferença deve-se ao fato de que culturalmente, a região Sul tem produtos e sabores diferentes das 
demais regiões brasileiras (Beluzzo, 2004), pois sofreu maior influência de diversos colonizadores europeus (Araujo et al., 2005), formando um grupo social e cultural específico no Brasil (Cerdan, 2009).

Um dos motivos para a opção dos hotéis do Nordeste e do Sul pelas grandes quantidades de preparações regionais no café da manhã pode ser explicada por Chaves et al. (2009), que em sua pesquisa analisou cardápios de escolas públicas na região Sul, onde em $86,5 \%$ dos cardápios de merenda escolar, apresentaram de uma a três preparações regionais por semana, na região Sudeste $84 \%$ dos cardápios continham pelo menos uma preparação regional por semana. Na região Centro-Oeste, 59\% dos cardápios apresentaram de uma a duas preparações regionais por semana. Na Região Nordeste, $84 \%$ dos cardápios apresentam ao menos uma preparação regional.

\section{Conclusão}

O tema escolhido é pouco estudado, coadunando com Sousa (2016), que diz que o tema "Café da manhã" é pouco descrito e o enfoque no consumo de alimentos regionais é mais carente de descrição. A revisão bibliográfica se apresentou escassa de informações, muitas vezes cabendo relacionar artigos das áreas de nutrição, Gastronomia, Hotelaria e antropologia da alimentação.

Conclui-se que existem diferenças regionais entre o café da manhã da rede hoteleira quando tratamos da inclusão de alimentos regionais. Foi constatado que existe uma preferência nacional pelos alimentos regionais que é pouco oferecida nos cafés da manhã de hotéis, demonstrando um potencial inexplorado pelo trade hoteleiro nacional. Pesquisas mais abrangentes e mais aprofundadas seriam de grande contribuição para ratificar a ideia de que a cozinha regional pode e deve ser mais explorada, tanto pelo lado comercial quanto pelo lado cultural.

\section{Referências}

Affenito, S. G. (2007). Breakfast: A Missed Opportunity. Journal of the American Dietetic Association, 107(4), 565-569, https://doi.org/10.1016/j.jada.2007.01.011.

Araujo, W. M. C., Botelho, R. B. A., Ginani, V. C., Araújo, H. M. C., \& Zandonadi, R. P. (2005). Da alimentação à gastronomia. Brasília: Editora Universidade de Brasília. p. 55-65.

Bastos, D. C., Passos, O. S., Nascimento, F. S. S., \& Nascimento, S. D. S. (2012). Caracterização físico-química de frutos de laranja no Vale do São Francisco. In Embrapa Semiárido-Artigo em anais de congresso (ALICE). In: congresso brasileiro de fruticultura, 22. Bento Gonçalves.

Beluzzo, R. (2004) A valorização da cozinha regional. In: 1ªcongresso Brasileiro De Gastronomia E Segurança Alimentar, 1. Brasília-DF. Brasília: UnB.

Brasil (2015). Ministério da Saúde. Secretaria de Atenção à Saúde. Departamento de Atenção Básica. Alimentos regionais brasileiros / Ministério da Saúde, Secretaria de Atenção à Saúde, Departamento de Atenção Básica. (2a ed.), Ministério da Saúde, 484 p.

Bueno, C. (2016). Febre culinária. Ciência e Cultura, 68(1), 63-65. https://dx.doi.org/10.21800/2317-66602016000100020

Canesqui, A. M., \& Garcia, R. W. D. (2005). Antropologia e Nutrição: um diálogo possível. Rio de Janeiro: Editora FIOCRUZ, p.129-145.

Carvalho, M. S. (2008). Lugares e paladares: uma contribuição geográfica à diversidade do consumo alimentar no Brasil. Revista RA $E$ GA, editora UFPR, 15, 95-111.

Cascudo, L. da C. (2017). História da alimentação no Brasil. Global Editora e Distribuidora Ltda.

Cerdan, C. (2009) Valorização dos produtos de origem e do patrimônio dos territórios rurais no sul do Brasil: Contribuição para o desenvolvimento territorial sustentável. Política \& Sociedade, 8(14), 277-300. https://doi.org/10.5007/2175-7984.2009v8n14p277.

Conceição, J., Barbosa, A., Silva, I., Freitas, F., \& Camilo, V. (2021). Fichas Técnicas de Preparações Regionais como instrumento para preservação da identidade cultural. DEMETRA: Alimentação, Nutrição \& Saúde, 16, e57174. https://doi.org/10.12957/demetra.2021.57174.

Corção, M. (2014). Câmara Cascudo, o “provinciano incurável”: desvendando os caminhos de história da alimentação no brasil. 279fls. Tese (Doutorado) Universidade Federal do Paraná. Curitiba.

Dimenstein, R., Bezerra, D. S., de Araujo, K. F., Martins, G. M., \& de Lima Azevedo, C. J. (2010). Alimentos regionais fontes de vitamina a conhecidos por parturientes atendidas em maternidade pública. Revista Extensão \& Sociedade, 1(2).

Fisberg, M., Wehba, J., \& Cozzolino, S. M. F. (2002). Um, dois, feijão com arroz: a alimentação no Brasil de Norte a Sul. Editora Atheneu, 2002. 418 p. 
Freyre, G. (2020). Açúcar: uma sociologia do doce, com receitas de bolos e doces do Nordeste do Brasil. Global Editora.

Hernández, J. C. (2005). Patrimônio e globalização: o caso das culturas alimentares. Antropologia e nutrição: um diálogo possível, $129-145$.

Lody, R. (2019). Coco: comida, cultura e patrimônio. Editora Senac São Paulo.

Maciel, M. E. (2004). Uma cozinha à brasileira. Revista Estudos Históricos, 1(33), 25-39.

Maior, M. S. (2004) Comes e Bebes do Nordeste. Fundação Joaquim Nabuco. 190p.

Mendoza, V. S., Santos, L. L., \& Sanjinez-Argadoña, E. J. (2016). Elaboração de granola com adição de polpa e castanha de bacuri para consumo com iogurte. Evidência, 16(2), 83-100.

Ministério Da Saúde. (2014). Guia alimentar para a população brasileira. (2a ed.), Ministério da Saúde, 2014. https://bvsms.saude.gov.br/bvs/publicacoes/guia_alimentar_populacao_brasileira_2ed.pdf.

Mullan, B. A., \& Singh, M. (2010) A systematic review of the quality, content, and context of breakfast consumption. Nutrition \& Food Science, 40(1), 81114. https://doi.org/10.1108/00346651011015953.

Ribeiro, M. I., Matos, A., Almeida, A. D. S., Fonseca, A., Fernandes, B., Mota, C., Guedes, H., Rodrigues, M., Neto, M., \& Abreu, R. (2009). Produtos alimentares tradicionais: hábitos de compra e consumo do mel. Revista de Ciências Agrárias, 97-112.

Santana, A. G., Costa, M. L. G., \& Shinohara, N. K. S. (2021). Alimentação em tempos de pandemia do Coronavírus: a ressignificação de uma prática cotidiana e dietética. Research, Society and Development, 10(3), e50410313442-e50410313442.

Santana, P. S., \& Alves, T. C. H. S. (2022). Consequências da seletividade alimentar para o estado nutricional na infância: uma revisão narrativa. Research, Society and Development, 11(1), e52511125248-e52511125248.

Santos, M. C. L., Mendonça, C. M., \& Shinohara, N. K. S. (2020). Milho e o São João: Identidade Gastronômica. Revista Contexto da Alimentação: Comportamento, Cultura e Sociedade. 8(1), 33-44p.

Santos, V. F. N., \& Pascoal, G. B. (2013). Aspectos gerais da cultura alimentar paraense. Revista da Associação Brasileira de Nutrição, 5(1), 73-80.

Shinohara, N. K. S., Veloso, R. R., Borckmans, M. V. L., Alexandre, E. F., \& Padilha, M. R. F. (2014). Macaxeira na cultura alimentar pernambucana.7(2), 86-102.Revista Eletrônica "Diálogos Acadêmicos".

Silva, A. B. (2010). Perfil nutricional da clientela atendida nos restaurantes comunitários do Distrito Federal. 2010.109 f. Dissertação (Mestrado em Nutrição Humana) - Universidade de Brasília, Brasília, Distrito Federal.

Silva, N. O., Lima, L. F., Natel, A. S., Bianchini, H. C., \& Silva, A. B. (2022). Plantas alimentícias não convencionais produzidas no sul de Minas Gerais. Research, Society and Development, 11(1), e51211125159-e51211125159.

Sousa, J. R. (2016). Café da manhã: aspectos nutricionais e culturais entre frequentadores adultos de restaurantes populares do Brasil. 2016.232 f. Tese (doutorado) - Universidade de Brasília, Brasília. http://www.sbicafe.ufv.br/handle/123456789/12303.

Souza, A. D. M., Pereira, R. A., Yokoo, E. M., Levy, R. B., \& Sichieri, R. (2013). Alimentos mais consumidos no Brasil: Inquérito nacional de alimentação 2008-2009. Revista de Saúde Pública, 47, 190s-199s.

Timlin, M. T., \& Pereira, M. A. (2007). Breakfast frequency and quality in the etiology of adult obesity and chronic diseases. Nutrition reviews, 65(6), 268281.

Trintin, B. C., \& Hahn, R. C. (2021). Análise do resultado econômico em relação a opção de faturamento do café da manhã em uma empresa hoteleira: um estudo de caso. Revista Eletrônica de Ciências Contábeis, 10(1), 1-30.

Uggioni, P. L. (2006). Valorização do Patrimônio Gastronômico Regional Açoriano: Gestão de Qualidade em Restaurantes Típicos em Florianópolis-SC. 265f. Dissertação (Mestrado em Nutrição) - Universidade Federal de Santa Catarina, Santa Catarina

Uribe, A. C. R., Avalos, E. A. G., \& Villa, J. M. Q. (2017). Educación en gastronomía: su vínculo con la identidad cultural y el turismo. El Periplo Sustentable. 32. <https://rperiplo.uaemex.mx/article/view/4880>.

Veloso, R. R., Shinohara, N. K. S., Padilha, M. R. F., \& Matsumoto, M. (2019). Construção da Cultura Alimentar Mexicana. Contextos da Alimentação Revista de Comportamento, Cultura e Sociedade 7(2). Centro Universitário Senac

Zuin, L. F. S., \& Zuin, P. B. (2009). Alimentação é cultura: aspectos históricos e culturais que envolvem a alimentação e o ato de se alimentar:[revisão]. Nutrire Rev. Soc. Bras. Aliment. Nutr, 225-241. 